\title{
Using involvement to reduce inconsistencies in risk preference elicitation
}

\section{Journal Article}

\section{Author(s):}

Meraner, Manuela; Musshoff, Oliver; Finger, Robert (iD)

Publication date:

2018-04

Permanent link:

https://doi.org/10.3929/ethz-b-000250839

Rights / license:

Creative Commons Attribution-NonCommercial-NoDerivatives 4.0 International

Originally published in:

Journal of Behavioral and Experimental Economics 73, https://doi.org/10.1016/j.socec.2018.01.001 


\section{Postprint}

This is the accepted version of a paper published in the Journal of Behavioral and Experimental Economics. This paper has been peer-reviewed but does not include the final publisher proofcorrections or journal pagination.

\section{Citation for the original published paper:}

Meraner, M., Musshoff, O., Finger, R. (2018). Using involvement to reduce inconsistencies in risk preference elicitation. Journal of Behavioral and Experimental Economics 73, 22-33 https://doi.org/10.1016/i.socec.2018.01.001

Access to the published version may require subscription.

N.B. When citing this work, cite the original published paper. 


\title{
Using involvement to reduce inconsistencies in risk preference elicitation
}

\begin{abstract}
Empirical research aiming to elicit risk attitudes faces problems of within- and betweenmethod inconsistencies, which reduce the explanatory and predictive power of risk research. In this paper, we investigate the relevance of context and task involvement on these inconsistencies. Our analysis is based on a sample of 244 German agricultural sciences students, which were performing an iterative multiple price list (iMPL) and a simple self-assessment question on risk preferences. We find that using a real life and subject context specific (here, agricultural) framing of the IMPL is leading to fewer within- and between-method inconsistencies. This is due to the fact that contextual framing has an increasing effect on task involvement (proxied with the time spent in the iMPL). Additionally, we find that contextual framing triggers the role of subjects' context involvement (proxied using an indicator for students' involvement in the agricultural domain). More specifically, both higher task and context involvement are found to decrease within-method inconsistency in the iMPL task. While also between-method inconsistency is decreasing in subjects' task involvement, we found no effect of context involvement. In conclusion, our results suggest that by framing a risk elicitation method according to the subjects' specific context, involvement can be triggered and inconsistencies and misspecifications can be reduced.
\end{abstract}

Keywords: Between- and within-method inconsistencies, risk preference elicitation, involvement

JEL Classifications: C91 D81

\section{Introduction}

The extent to which people are willing to take on risk constitutes their risk attitudes, which in turn plays a major role in explaining their behavior. Consequentially risk attitudes are of high importance for decisions in many economics-related contexts. Understanding individual attitudes towards risk is closely linked to the goal of understanding and predicting economic behavior and giving policy advice.

There is a growing literature on how to measure risk attitudes and accordingly a large body of literature focuses on the selection of the right elicitation method (for an extensive overview see Charness et al., 2013). Many of these methods are based on the same theoretical foundation of expected utility theory (EUT) and thus claim to measure the subjects' "true" risk preference. Consequently, risk preferences elicited using different methods should be comparable and accurate. However, because of inconsistencies (i.e. errors) in the individuals' responses these 
criteria are often not met in empirical work by the participants (Csermely and Rabas, 2017). More specifically, three ways of consistency are distinguished in the literature i) between-method consistency of several elicitation methods (Crosetto and Filippin, 2013; Dohmen et al., 2011; Eckel and Grossman, 2002), ii) within-method consistency of the same elicitation method at one point in time (Holt and Laury, 2002; Jacobson and Petrie, 2009), and iii) within-method consistency of the same elicitation method over two points in time (Andersen et al., 2008; Harrison and Rutström, 2008). Inconsistencies lead to biases in the interpretation of the decision makers' risk preferences and consequently biased inferences on human behavior and policy recommendations. In order to overcome these inconsistency problems, past research has frequently reached out to new methods to elicit risk preferences (Charness et al., 2013). This did not necessarily result in lower inconsistencies but contributed to increasing problems of comparability of the different studies. Furthermore, a large body of literature seeks to identify the correct assumptions about the nature of the data gathered and thus 'errors' made by the subjects in the experiments generating the data under analysis (Carbone and Hey, 2000; Wilcox, 2008).

Based on the seminal work of Kahneman and Tversky (1979), numerous studies have shown that decision making is strongly influenced by the decision frame (i.e. decision makers respond differently to different but objectively equivalent descriptions of the same problem). Furthermore, Kahneman (2003) defined two different ways of processing information applied in different contexts of decision making depending on the motivation and capability of the decision maker. The motivation of subjects is expected to be dependent on the subject-specific relevance of the task, or, in other words, the subjects' involvement with it. The subject-specific relevance is expected to be influenced by the decision frame, so that framing can trigger task involvement.

And indeed, there is evidence in different experimental settings that the application of context is enhancing understanding of experimental tasks, reduces mistakes and increases quality of results (see Alekseev et al., 2017 for an extensive overview). However, there is evidence of heterogeneity with respect to how people respond to contextual changes. Alatas et al. (2009) find that expert subjects relate better to contextual framing than students. However, using student subject pools have a long tradition in experimental economics, due to amongst other reasons, the possibility of cost saving and convenience/availability of students. Thus, we focus on framing effects targeting the students and include the students' specific involvement with the contextualization.

We aim to close the gap in the literature and to reduce inconsistencies by including contextual framing and personal involvement in the risk elicitation research design. More specifically, we show in this paper that risk preference elicitation methods evoke fewer between-method and within-method inconsistencies when specific task and context involvement is included in the analysis. In our analysis, task involvement is determined by the decision makers' task related effort. In contrast, context involvement is defined by the personal relevance of the task for the decision maker. 
The remainder of this paper is organized as follows. First, we give an overview on the existing literature concerning risk preference elicitation and inconsistencies. Next, an introduction to the experimental design and methodology used in this analysis is presented. The subsequent description of the data sample and results of this research is followed by the conclusion.

\section{Literature background}

Over the last decade approximately 20 new methods to elicit risk preferences have been published (for a detailed overview on the most established ones see Charness et al., 2013). Along these lines, there is growing literature on comparing experimental methods to measure risk preferences (e.g. Coppola, 2014; Crosetto and Filippin, 2013; Csermely and Rabas, 2017).

A very popular method to elicit risk preferences is via a Multiple Price List (MPL), where subjects are presented with a series of choices between gambles. This approach allows to estimate intervals for the curvature parameters of a utility function for each subject. However, since the inference of risk preferences, and in turn, parameter estimation, requires a unique switching point respondents with more than one switching point are not behaving consistently under standard EUT assumptions on preferences (Charness et al. 2013). The problem of inconsistencies in MPL tasks is highly relevant in empirical research on experimental risk preference elicitation methods. For instance, Charness and Viceisza (2016) found that 75\% of Senegalese farmers made inconsistent choices, Hirschauer et al. (2014) found 57\% inconsistent answers amongst Kazakh farmers, and, using a sample of adults in Ruanda, Jacobson and Petrie (2009) found an inconsistency rate of 55\%. High inconsistency rates are also observed in developed countries: e.g. Lévy-Garboua et al. (2012) find that on average around 36\% of French students behave inconsistently in different MPL settings, Holt and Laury (2002) find 13\% inconsistent answers amongst students in the USA and Dave et al. (2010) find $8.5 \%$ of participants answering inconsistently in a sample of Canadian citizens. The main problem of data containing inconsistencies is related to the different ways of dealing with inconsistencies to interpret risk preferences. Most researchers choose to either ignore subjects with inconsistent choices or to make specialized assumptions on the nature of stochastic errors and estimate the parameters of interest (Jacobson and Petrie, 2009). Excluding inconsistently behaving subjects, results in a biased sample since systematic differences may exist in the risk preferences of consistent and inconsistent participants (see Jacobson and Petrie (2009) for more details on behavioral patterns of subjects making mistakes). When including inconsistently responding subjects in the estimation of the risk aversion parameter, a stochastic error term (i.e. 'structural noise') parameter is often included in the estimation (see e.g. Carbone and Hey, 2000; Harrison and Rutström, 2008).

Three driving factors explaining between- and within-method instability of risk preference elicitation have been identified in the literature: i) differences in the cognitive ability of subjects and task complexity (Anderson and Mellor, 2009; Dave et al., 2010; Lévy-Garboua et al., 2012), ii) misspecification of individual preferences (Harrison et al., 2007; Starmer, 2000) and iii) contextdependence of risk preferences (Deck et al., 2014; Holt and Laury, 2002, 2005). 
One way to overcome problems with inconsistencies stemming from the subject pools cognitive abilities or complexity of the task is to use simpler risk preference elicitation methods. Dave et al. (2010) perform experiments on subjects with different mathematical ability. They conclude that a simpler elicitation method results in higher within-method consistency for subjects with lower mathematical ability. However, simpler alternative risk elicitation methods imply a loss of comparability and accuracy. Furthermore, Bruner (2009) and Lévy-Garboua et al. (2012) explore how different ways of displaying the choice sets affect inconsistency rates. Bruner (2009) finds less within-method inconsistencies for a menu displayed lottery frame with increasing probabilities vs. increasing reward. Lévy-Garboua et al. (2012) find more inconsistent behavior with a sequential presentation of decisions compared to a simultaneous presentation of all ten decisions and increasing presentation of probabilities Based on these results, Lévy-Garboua et al. (2012) conclude that inconsistencies with a bad frame, in terms of visual presentation of the MPL, are driven by a lack of information. In a similar vein, Andersen et al. (2008) find cognitively more challenging tasks (risk preference vs. time preference elicitation), to induce more noise in the estimated parameter.

To overcome inconsistencies, due to misspecifications in the underlying theoretical model. Some include elements of prospect theory e.g. loss aversion and probability weighting to characterize risk attitudes (for a detailed comparison of different underlying theoretical concepts see Abdellaoui et al., 2011). Other authors interpret inconsistencies as indifferences and hence adapt the original design of the MPL i) by including a third choice in each row indicating indifference in preference between both lotteries (Andersen et al., 2008) or ii) by enforcing a unique switching point (see (see Andersen et al., 2006; Harrison et al., 2007) ). The latter imposes strict monotonicity on revealed preferences and enforces transitivity. As there is no further control mechanism to ascertain whether all participants understood the task, this might cause biases of the results and, in turn, biases of the estimated preferences.

Moreover, inconsistencies have been found to be context and stake dependent. For instance, Holt and Laury (2002); (2005) find that inconsistencies can be reduced by increasing the payoff level. The importance of the effect of decision frames on risk preferences has been widely recognized in the literature on decision making analysis (Levin et al., 1998; Tversky and Kahneman, 1986). Specifically, Deck et al. (2014) find that fewer inconsistencies occur if the MPL is framed as financial investment task compared to a lottery task. They, however, used a very general setting without accounting for the specific background of the participants. Thus, we aim to extend the existing literature by focusing on the role of the subjects' contextual and task involvement when analyzing inconsistencies and the effects of different decision frames.

Based on McElroy and Seta (2003), we define task involvement as the personal effort, motivation and capacity to perform the task at hand (we use the time spent on a specific task as proxy). Context involvement is defined as the personal relevance of the task for the decision maker (we use an involvement score based on the student's involvement with the agricultural domain to measure context involvement). McElroy and Seta (2003) assume increasing task involvement with increasing context involvement, or more specifically the motivation and capacity to solve a 
problem is expected to increase with increasing personal relevance of the problem at hand. Furthermore, they differentiate two ways of processing decision problems ${ }^{1}$ arising from different levels of task and context involvement of the decision maker. In particular, McElroy and Seta (2003) find that holistic/heuristic processing occurs with low levels of motivation or capacity to solve a problem. Analytic/systematic thinking in turn sets in when the subject's motivation and ability are high ${ }^{2}$. Moreover, they conclude that with increasing relevance of the decision, the amount of effort expended on the task increases as well as the likelihood of analytic/systematic thinking. Subjects with a higher likelihood of exhibiting an analytic/systematic processing style are found to be more insensitive to the influence of framing effects.

However, this finding has not yet been considered in the approaches to reduce inconsistent behavior. Thus, we hypothesize that this is even more relevant if the investment task is placed in a subject specific setting. More specifically, we focus on agricultural students and formulate the financial investment task as agricultural investment decision to be taken by the participants. Furthermore, we measure the degree of context involvement in agricultural activities for each participant and test the influence of context involvement on consistency.. Given the relevance of both between-method and within-method consistency (Csermely and Rabas, 2017), we aim to address both problems in our analysis. To this end, we consider "within-method consistency" i.e. consistent behavior within the MPL at one point in time and "between-method consistency" i.e. consistent behavior in different elicitation methods. We use the subject's task involvement (i.e. time spent on the risk elicitation task) to test the influence on within-method inconsistencies. We hypothesize that both: within- and between method consistency increases with increasing task and context involvement.

Furthermore, we use two different frames of the MPL to test the influence of contextualization on the consistent behavior between different risk preference elicitation methods (MPL and selfassessment). Following earlier studies e.g. Anderson and Mellor (2009), Charness and Viceisza (2016), Dohmen et al. (2011) and (Thoma, 2015), we compare risk preferences elicited using incentivized methods (MPL) and not incentivized methods (self-assessment).

\section{Experimental design and methodology}

We focus on a homogeneous sample of students to reduce the influence of factors not controlled for in the study. More specially, we conducted the survey with agricultural science students at the two largest agricultural departments in the state of North-Rhine Westphalia (Germany), i.e. the University of Bonn and the South Westphalian University of Applied Sciences ${ }^{3}$. All students in agricultural sciences in both universities were invited to participate in two identical online surveys conducted in January and March 2015, respectively. Invitations where sent out via e-mail

\footnotetext{
${ }^{1}$ Their approach follows lines of earlier research see e.g. Stanovich and West (1999) and Tversky and Kahneman (1986).

${ }^{2}$ Kahneman (2003) uses the terms system 1 thinking and system 2 thinking.

${ }^{3}$ About 1,100 and 500 students are enrolled in agricultural sciences programs of the faculty in Bonn and Soest, respectively.
} 
including, information on the duration of the survey and the three weeks online period of the survey. We aligned the list of participating students with the university administrative offices' database, ensuring that the individual student e-mail address used to complete the survey corresponds to students enrolled in agricultural studies. Students participating without being enrolled in agricultural studies at the time the survey was realized are excluded from further analysis ${ }^{4}$. The experiment was conducted in two parts. Part I consisted of two risk-aversion tasks as explained in more detail in the following and part II consisted of a questionnaire collecting subjects' socio-demographic characteristics. Specifically, we collected information on age, sex, optimism and mothers' highest educational degree and risk literacy. For the latter, we used the Berlin numeracy test described in Cokely et al. (2012) $)^{5}$. Additionally, we included in this section specific characteristics to measure the students' context involvement (i.e. growing up on a farm holding, parents are farmers, planned succession of a farm, type and length of specific agricultural education).We measured the time each participant spent on each part of the questionnaire and use the time spent on the iterative Multiple Price List (iMPL) as proxy for task involvement. A complete documentation of all variables included in the survey is available in the Data in Brief paper accompanying this article(Meraner et al. (submitted along with this article))

To elicit risk preferences we use two methods dominant in the literature: a self-assessment of general risk preferences, and an iterative Multiple Price List (iMPL), an extension of the MPL. We include two different decision frames in our experiment, i.e. two different wordings that change the contextual setting of the iMPL. Additionally, we randomize the order of the two risk preference elicitation tasks (self-assessment and $\mathrm{iMPL}$ ). By using a randomization of the task sequence as well as randomly assigning each participant only one frame, we aim to control for potential biases arising from the sequence of tasks ${ }^{6}$. The instructions to the risk elicitation tasks presented to the subjects are available in Appendix B in the Data in Brief paper accompanying this article(Meraner et al. (submitted)) $)^{7}$.

\section{The self-assessment of risk preferences}

The self-assessment of general risk preferences follows earlier research and is based on a 11-point Likert scale (Charness and Viceisza, 2016; Dohmen et al., 2011; Thoma, 2015). The exact wording is taken from the German Socio-Economic Panel Study (SOEP), which is (translated from German)

\footnotetext{
${ }^{4}$ There is no information on students who did not select to participate but we targeted a very homogenous group of students see Harrison et al. (2009) for an analysis of selection effects stemming from voluntary participation

${ }^{5}$ We also tested the effects of these characteristics on risk aversion, but do not find significant effects, which is in line with similar research (e.g. Deck et al., 2014). This inexistence of significant effects of participants' characteristics is expected to be caused by the very homogenous sample used in this study. The results are not presented here but are available upon request from the authors.

${ }^{6}$ Harrison et al. (2005) argue that the Holt and Laury (2002) result of increasing risk aversion with increasing stakes could be a result of order effects, in a response by Holt and Laury (2005) confirmed the influence of order effects on risk preferences for real payments. Our results showed no significant influence of the task order on risk aversion.

${ }^{7}$ The full survey is available in German upon request.
} 
as follows: "How do you see yourself: are you generally a person who is fully prepared to take risks or do you try to avoid taking risks? Please tick a box on the scale, where the value 0 means: 'not at all willing to take risks' and the value 10 means: 'very willing to take risks'." (Wagner et al., 2007).

\section{The iterative Multiple Price List}

The iterative Multiple Price List (iMPL) is an extension of the basic MPL developed by Harrison et al. (2007). It elicits risk preferences, resulting in a more refined description of the subjects risk preferences compared to the standard MPL. The standard MPL as introduced by Holt and Laury (2002) is structured as follows: The table has ten rows and two columns; in each row the subjects face two gambling choices $A$ and $B$. Table 1 illustrates the basic payoff matrix presented to the subjects. Note that only the left side of the table is shown to the participants (i.e. not showing the expected value of option $A$ and $B$, the difference of expected values and the constant relative risk aversion (CRRA) interval). The subjects are asked to choose either A or B in each row. The intuition behind this test for risk aversion is that only very risk-loving subjects would take option $B$ in the first row, and only very risk-averse subjects would take option $A$ in the second-last row. The last row has no relevance for risk aversion, and is simply a test that the subject understood the instructions. Only choosing option $B$ is a rational choice, independent of the level of risk aversion. $A$ risk-neutral subject should switch from choosing $A$ to $B$ when the difference of expected values $A(E V A)$ and $B(E V B)$ is the smallest (see right side of Table 1), so a risk-neutral subject would choose $A$ for the first four rows and $B$ thereafter.

Table 1: Standard payoff table MPL

\begin{tabular}{|c|c|c|c|c|c|c|c|}
\hline Option A & & Option B & & EVA $^{\text {a) }}$ & EVBa) & Difference ${ }^{a)}$ & $\begin{array}{l}\text { Open CRRA } \\
\text { interva|a) b) }\end{array}$ \\
\hline$p(40 €)$ & $p(32 €)$ & $p(77 €)$ & $\mathrm{p}(2 €)$ & & & & \\
\hline $10 \%$ & $90 \%$ & $10 \%$ & $90 \%$ & 32.80 & 9.50 & 23.30 & $r<-1.71$ \\
\hline $20 \%$ & $80 \%$ & $20 \%$ & $80 \%$ & 33.60 & 17.00 & 16.60 & $-1.71<r \leq-0.95$ \\
\hline $30 \%$ & $70 \%$ & $30 \%$ & $70 \%$ & 34.40 & 24.50 & 9.90 & $-0.96<r \leq-0.49$ \\
\hline $40 \%$ & $60 \%$ & $40 \%$ & $60 \%$ & 35.20 & 32.00 & 3.20 & $-0.50<r \leq-0.14$ \\
\hline $50 \%$ & $50 \%$ & $50 \%$ & $50 \%$ & 36.00 & 39.50 & -3.50 & $-0.15<r \leq 0.15$ \\
\hline $60 \%$ & $40 \%$ & $60 \%$ & $40 \%$ & 36.80 & 47.00 & -10.20 & $0.16<r \leq 0.41$ \\
\hline $70 \%$ & $30 \%$ & $70 \%$ & $30 \%$ & 37.60 & 54.50 & -16.90 & $0.42<r \leq 0.68$ \\
\hline $80 \%$ & $20 \%$ & $80 \%$ & $20 \%$ & 38.40 & 62.00 & -23.60 & $0.69<r \leq 0.97$ \\
\hline $90 \%$ & $10 \%$ & $90 \%$ & $10 \%$ & 39.20 & 69.50 & -30.30 & $0.98<r \leq 1.37$ \\
\hline $100 \%$ & $0 \%$ & $100 \%$ & $0 \%$ & 40.00 & 77.00 & -37.00 & $r>1.37$ \\
\hline
\end{tabular}


Source: Own depiction according to Holt and Laury (2002) and Harrison et al. (2007). Note: all currency units are in EURO at the time of the experiment 1 USD $=0.86$ EURO. Note that the returns have been scaled up by a thousand tokens. a) Not shown to participants; b) Assuming a power utility function $U(x)=(1-r)^{-1} x^{1-r}$.

To analyze the data obtained in terms of coefficients of risk aversion we assume under EUT the subjects' utility function to have the following CRRA form: $U(x)=(1-r)^{-1} x^{1-r}$, where $x$ is the lottery price (investment return) and $r \neq 1$ the parameter of risk aversion to be estimated. With this functional form, $r=0$ denotes risk-neutral behavior, $r>0$ denotes risk aversion, and $r<0$ denotes risk-loving behavior. By minimizing the difference in expected utilities obtained from option $A$ and option B we can calibrate the open CRRA interval in the last column of Table $1^{8}$. In the iMPL the subjects are presented a second table with probabilities altering in-between the switching point of the first basic MPL. Hence, all participants are presented a maximum of twenty choices i.e. two tables with ten rows each. Assume, for example, that a subject switches in the first table in the third row from $A$ to $B$ (note that this is the same as to say the subject has chosen two safe choices). This choices result in a risk aversion coefficient within the interval between -0.96 and -0.49 in the first table, i.e. is risk loving. The second table that is shown to the participant would then consist of ten rows and two choices $A$ and $B$ with increasing probabilities ranging from $21 \%$ to $30 \%$ for option $A$ and $79 \%$ to $70 \%$ for option $B$, respectively. When adding the second table and assuming the switching point is here also at row three, the risk aversion coefficient interval is narrowed down and is now located within the interval between -0.84 and $-0.79^{9}$. To analyze the subject's degree of risk aversion we follow Harrison et al. (2007) and calculate the mid-point of the CRRA interval. Consequently the $\mathrm{MMP}$, compared to the standard MPL, allows a richer characterization of the utility function and thus a more refined elicitation of the true risk attitude (Harrison et al., 2007).

In order to estimate the individuals' parameter of risk aversion we are essentially estimating the likelihood to switch from option A to option B in each row. The stochastic choice process specifies the likelihood of choosing one option given an alternative option (for refinements on stochastic choice processes see Harrison and Rutström, 2008). Under EUT the expected utility of each outcome $k$ in each lottery $i$ is the probability weighted utility of each outcome in each lottery: $\mathrm{EU}_{\mathrm{i}}=\sum \mathrm{k}=1, \mathrm{k}\left(\mathrm{p}_{\mathrm{k}} \times \mathrm{U}_{\mathrm{k}}\right)$, with $p_{\mathrm{k}}$ being the probabilities for each outcome. Following Abdellaoui et al. (2011); Andersen et al. (2008) and Holt and Laury (2002) we use the Luce error ${ }^{10}$ specification to estimate the likelihoods conditional on the model: $\nabla E U=\mathrm{EU}_{B}{ }^{(1 / \mu)} /\left(\mathrm{EU}_{A}{ }^{(1 / \mu)}+\mathrm{EU}_{B}{ }^{(1 / \mu)}\right)$, where $\mathrm{EU}_{A}$ is

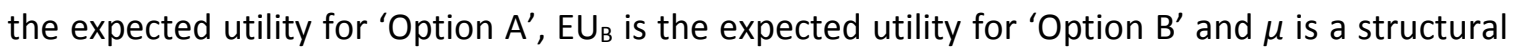
noise parameter. This enables us to include individuals' choices that are not consistent with standard EUT assumptions when estimating $r$ based on a EUT model. The log-likelihood of the risk aversion response, conditional on the EUT and CRRA specifications being true, depends on the estimates of $r$ and $\mu$. The likelihood of risk aversion can be written as

\footnotetext{
${ }^{8}$ Note that these CRRA intervals are the same as reported by Holt and Laury (2002) (Table 3).

${ }^{9}$ The full table of resulting CRRA intervals is available upon request from the authors.

${ }^{10}$ See Harrison and Rutström (2008) for refinements on stochastic choice processes as well as a detailed comparison of Fechner and Luce error specification.
} 
$\operatorname{lnL}(r, \mu ; y, X)=\sum_{i}\left(\left(\ln \left(\nabla E U \mid y_{i}=1\right)+\left(\ln \left(1-\nabla E U \mid y_{i}=-1\right)\right)\right.\right.$, where $y i=1(-1)$ denotes the choice of the option $\mathrm{B}(\mathrm{A})$ in risk aversion task $i$ and $X$ is a vector of individual characteristics.

Following Harrison et al. (2007) the iMPI uses the same incentive logic as the MPL. The participants were asked prior to the iMPL to answer a control question about the payoff procedure, which ensures that all participants understood the payoff structure and in turn incentive compatibility of the iMPL. For $10 \%$ of all participants one row is chosen randomly from the first table to be relevant for payoff. Depending on the subjects choices and a randomly chosen number between 1 and 100 (reflecting the probabilities of payoff for option A and B) the individual payoff is determined. If the row chosen at random is not the row where the subject switched from $A$ to $B$ the payoff determining process ends here (identical to the MPL payoff procedure). If the row chosen is the row that the subject switched at, another random draw is made to pick a row in the second table that the subject was presented with. The subject's choice in the second drawn row is then relevant for payoff and the procedure to determine the payoff is the same as described above $^{11}$. At the end of the experiment, for $10 \%$ of the subjects, one choice was randomly selected to be played out for real ${ }^{12}$. According to Baltussen et al. (2012) this between-subjects random incentive system, reduces the probability of real payoff for every task, possibly inducing lower task motivation. However, we opted for this incentive system because it allows higher prizes to be awarded to the subjects selected, which may improve motivation and reduces the high administrative costs related to paying each participant in a large online survey. ${ }^{13}$ Additionally, this payoff structure was successfully adopted in earlier research (e.g. Maart-Noelck and Musshoff (2013) and Vollmer et al. (2017)).Inconsistencies and contextualization

Different ways of inconsistent behavior, that is behavior not consistent with classical assumptions made in EUT, within the above presented IMPL are possible: $i$ ) inconsistent response behavior is revealed if more than one switching point between option $A$ and $B$ is observed; ii) inconsistent behavior is indicated by "backwards" choices, i.e. switching in the other direction from option $B$ in the first row to option A in the following rows (Holt and Laury, 2002; Lévy-Garboua et al., 2012) and iii) as the last set of choices is commonly a control question with option $B$ clearly dominating option $A$, a subject choosing $A$ in all 10 rows is also thought of behaving inconsistent. Because in the last row option B results with certainty in a higher payoff than option A (see also Table 1 for

\footnotetext{
${ }^{11}$ Participating students were asked to leave their unique university e-mail address enabling the researcher to contact them for the payoff. The random draws of winners and corresponding rows where carried out immediately after the participation deadline (average two weeks period). The winners were invited to pick up their prices in the faculty library, in cases when this was not possible payments where contacted and asked for further details to arrange a transfer of the prize to the student's bank account.

12 The expected return for each participant is $4 €$ for approximately 20 minutes time spent on the survey. The average hourly wage rate of students employed as assistants at Universities in North RhineWestphalia amounts to $8.50 €$, which is used as a reference for opportunity cost of participation. Consequently, the expected return of participating exceeds the opportunity cost, leading to an incentive compatible iMPL.

${ }^{13}$ See Baltussen et al. (2012) for a in depth discussion on the application of different incentive systems.
} 
an example). Note that in the iMPL there is a possibility of inconsistent behavior either in the first or in the second table. Both cases are in the following treated as within-method inconsistencies.

Based on the findings of Lévy-Garboua et al. (2012) and Holt and Laury (2002) we avoid excessively high inconsistency rates by showing probabilities simultaneously (i.e. the full table of choices at once) and using high payoff. The payoff are identical to the high payoff treatment of Holt and Laury (2002), this is the original lottery payoff X 20. Holt and Laury (2002) showed that this higher payment provokes higher risk aversion than the original low payoff lottery. However, real agricultural decisions are mostly involving high payoffs, thus a high scaled experiment is representing real life decisions more realistically. Note that in order to construct a realistic agricultural decision the returns in both frames (general lottery and agricultural decision) have been scaled up by thousand. The participants were informed about the exchange value for the real payoff in the control question prior to the iMPL.

We use two different contextual settings of the iMPL to analyze the effects of involvement. They are as follows: First, the traditional wording according to Holt and Laury (2002) of a gambling choice between two lotteries $A$ and $B$ with different payoff and associated probabilities. In the further this is referred to as 'general lottery' frame ${ }^{14}$. Second an agricultural decision with investment options $A$ and $B$ with different returns and associated probabilities. This is in the further referred to as the 'agricultural decision' frame. Note that no time components have been included in the task or task description. In contrast, it was very clear to the participants that payoffs are made shortly after the experiment was conducted (for both tasks). Two pre-test sessions with 19 students did neither reveal difficulties with respect to the experiments payoff structure or framing, nor indicated a misunderstanding regarding the time dimension of the agricultural investment decision. Thus, there is no evidence for time related biases in the agricultural investment frame (Deck et al., 2014). Nevertheless, investment decisions are undoubtedly closer to the real decisions subjects face in there every day life, justifying the chosen comparison. The specific application to agriculture makes use of the educational background of the participants. The wording of the agriculture specific question reads as following: "Assume that after successful completion of your studies you are offered to make an agricultural investment. Here you will get with different associated probabilities for investment $A$ a return of $40,000 €$ or $32,000 €$ and for investment $B$ a return of $77,000 €$ or $2,000 €$. You can choose in the following table in each row between the two investment options (A or B)."

In order to analyze the effect of task involvement on within-method consistency we compare the frequencies of inconsistent answers in the different iMPL frames depending on the individual task involvement. Additionally, we compare the structural noise $\mu$ when estimating the risk preference

\footnotetext{
${ }^{14}$ The exact wording of the general lottery task is as following: "In each row of the following table you can choose between two lotteries ( $A$ and $B$ ). With certain chances/ probabilities you get for lottery $A$ a payoff of $40.000 €$ or $32.000 €$ and for lottery $B$ a payoff of $77.000 €$ or $2.000 €$. Please decide between lottery $A$ and B for every row of the table."
} 
parameter $r$ for both frames and differences in context involvement using standard maximum likelihood procedures (following Harrison and Rutström, 2008).

To analyze whether between-method consistency increases with increasing context involvement we compare the correlation of risk aversion coefficients compiled using the two elicitation methods described above (iMPL and self-assessment ${ }^{15}$ ). Using the methodological steps suggested by Olkin and Finn (1995) and Steiger (1980), we compare the correlation of both risk elicitation methods in the two iMPL frames. The same approach is used to test if task involvement influences between-method consistency.

\section{Sample description and results}

We obtained 370 answers and 156 complete questionnaires from Bonn University and 194 answers with 96 complete questionnaires from the South Westphalian University of Applied Sciences leading to a total of 252 complete questionnaires (response rate of $34 \%$ and $15 \%$ complete responses). After the data cleansing process 244 surveys remained ${ }^{16}$. Due to strict data protection policies in both universities, only information on the agricultural students' gender was available. At Bonn University $43 \%$ male and $57 \%$ female agricultural students are enrolled, which is reflected as well in our sample. The consistent answers amount to 195. Among them, 95 were randomly assigned to the general lottery and 100 students were randomly assigned to the agricultural decision. Table 3 shows the summary statistics for the total sample, and Table 3 the summary statistics of the general lottery and the agricultural decision sample separately. Figure $1 \mathrm{~A}$ and $2 \mathrm{~A}$ in Appendix $\mathrm{A}$ in the accompanying Data in Brief paper (Meraner et al., submitted) provide additional insights into the distribution of risk preference estimates.

The mean CRRA interval mid-point indicates an average risk aversion coefficient of 0.57 , which is in line with other researchers findings (see Harrison et al., 2007). Furthermore, the selfassessment of the participants risk attitude is with an average of 4.64 also pointing towards risk aversion. Context involvement is defined as the personal relevance of the task for the decision maker. We calculate a context involvement score based on the student's agricultural involvement (referring to the specific agricultural contextualization used). This score includes the following factors: rural origin, farm upbringing, parents are farmers, succession of farm holding intended, agricultural internship, vocational training, and obtained agricultural education certificate. The average context involvement score is 1.74 points. The average task involvement measured by the time spent on the iMPL is 3.40 minutes, and the time spent on the self-assessment of risk preferences 0.43 minutes (see Table 3 for a detailed summary of variables). When comparing the sample with the general lottery framing and contextualized lottery we see lower average risk

\footnotetext{
15 To account for the ordinal structure of responses from Likert scale questions, we use rank correlations throughput the entire paper.

${ }^{16}$ Participants not enrolled in agricultural studies and non-German students were excluded to eliminate biases due to different educational and cultural differences we are not accounting for.
} 
aversion in the general lottery framed iMPL. Context involvement scores are on average higher in the sample randomly assigned to the contextualized $\mathrm{MMPL}^{17}$ (see Table 3).

In order to analyze the effect of task and context involvement on within-method consistency we first compare the frequencies of inconsistent answers in the different iMPL frames (see Table 2). A total of 49 students (20\%) answered inconsistently. This is comparable to inconsistency rates found among student samples by Lévy-Garboua et al. (2012) (36\%) and Holt and Laury (2002) (13\%). We group the students into a "high task involvement" group and a "low task involvement" group according to the time they needed to complete the iMPL. The cut-off value is the median time needed by the whole sample to complete the task. We see clearly more cases of inconsistent behavior in the group of students with low task involvement (28\%). In the high task involvement group only $12 \%$ behave inconsistently. The null hypothesis of independence of consistence of answers and task involvement can be rejected at the $1 \%$ level of significance.

Table 2: Contingency table of inconsistencies with different task involvement

\begin{tabular}{|c|c|c|c|c|}
\hline & Consistent & Inconsistent & Row Total & $\begin{array}{l}2^{\text {nd }} \text { table } \\
\text { inconsistent }\end{array}$ \\
\hline High Task Involvement & 107 & 15 & 122 & 6 \\
\hline Chi-square contribution & 0.928 & 3.684 & & \\
\hline$\%$ of total row & $88 \%$ & $12 \%$ & & $40 \%$ \\
\hline Low Task Involvement & 88 & 34 & 122 & 15 \\
\hline Chi-square contribution & 0.926 & 3.684 & & \\
\hline$\%$ of total row & $72 \%$ & $28 \%$ & & $48 \%$ \\
\hline Column Total & 195 & 49 & 244 & \\
\hline \multicolumn{5}{|c|}{ Pearson's Chi-squared test with Yates' continuity correction $=8.2738$} \\
\hline$p$-value $=0.004$ & & & & \\
\hline
\end{tabular}

We did not measure the time expended on the first and second table of the iMPL separately. Thus, it is important to note that $48 \%$ of the inconsistent subjects in the low involvement group and $40 \%$ of the inconsistent subjects in the high involvement group behaved inconsistently in the second table. Consequently, the bias in time measurement caused by the two tables of the iMPL can be neglected.

\footnotetext{
${ }^{17}$ We have further estimated a binary logit model using demographic characteristics of participants as independent variables and inconsistent behavior as dependent variable. However, this analysis did not result in statistically significant coefficient estimates (results are available upon request).
} 
Table 3: Summary statistics by frame and within method consistency

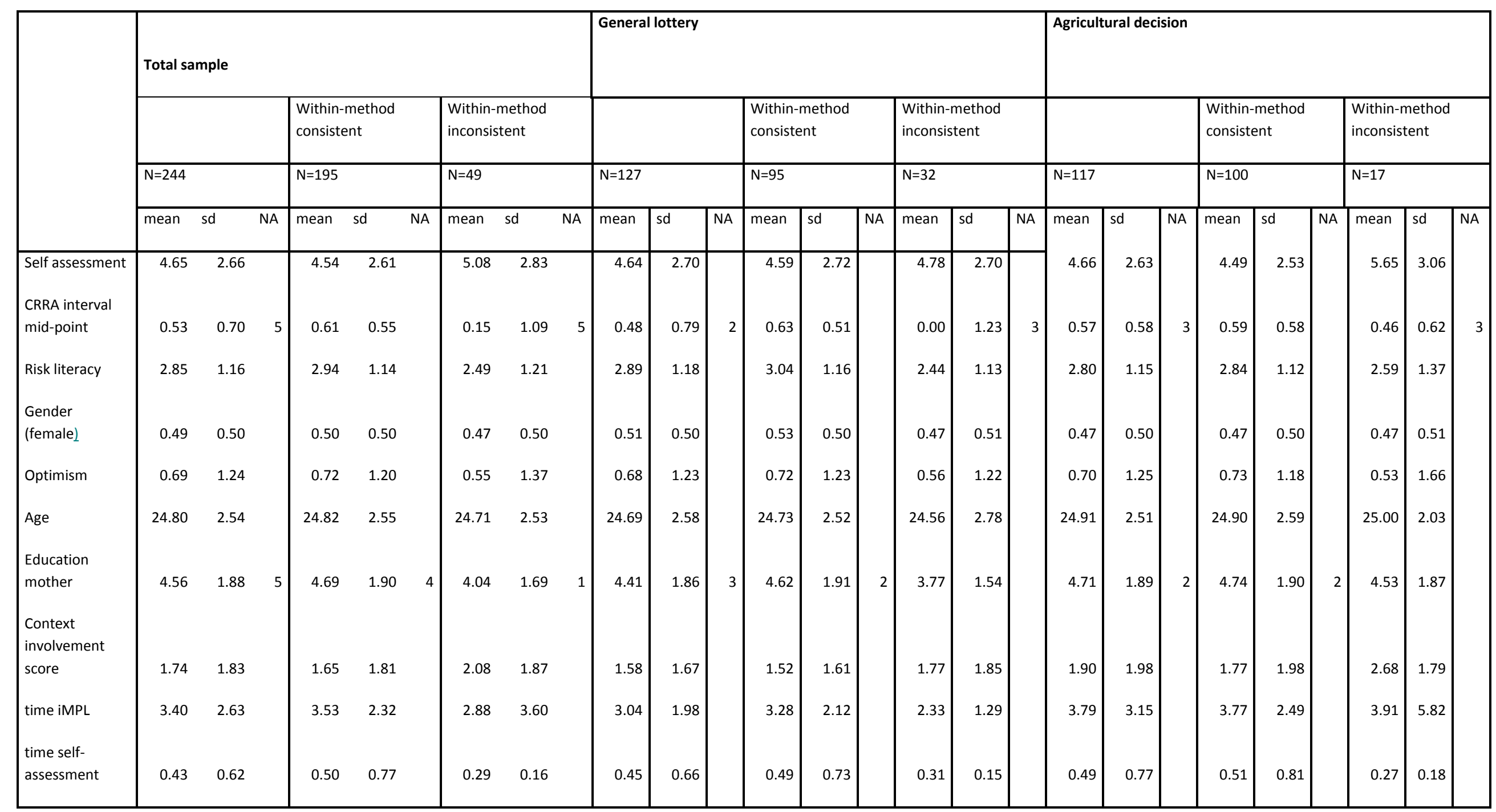


In addition, we analyze the influence of context involvement on within-method consistency (see Table 4). We see more cases of inconsistent answers in the general lottery frame (25\%) than in the agricultural decision frame (15\%). The null hypothesis of independence of consistence of answers and contextualization can be rejected at the $10 \%$ level of significance ${ }^{18}$, revealing a pattern of different inconsistency rates related to the different IMPL frames. Our approach differs from earlier work, e.g. by Deck et al. (2014), by placing the agricultural decision task in a subject specific setting. Based on this further specification of the framing, we can show that within-method consistency increases with contextualization of the task.

Table 4: Contingency table of inconsistencies in different context involvement

\begin{tabular}{l|ll|l}
\hline & \multicolumn{1}{|l|}{ Consistent } & Inconsistent & Row Total \\
\hline General lottery & 95 & 32 & 127 \\
Chi-square contribution & 0.416 & 1.655 & \\
\% of total row & $75 \%$ & $25 \%$ & $52 \%$ \\
Agricultural decision & 100 & 17 & 117 \\
Chi-square contribution & 0.451 & 1.796 & $48 \%$ \\
\% of total row & $86 \%$ & $15 \%$ & 244 \\
\hline Column Total & 195 & 49 & \\
\hline
\end{tabular}

Furthermore, we analyze maximum likelihood estimates of the individual risk aversion coefficient $r$ and the Luce noise parameter $\mu$ from our experiments. In this analysis, we also include the participants' agricultural context involvement. Our estimates in both frames show that there is significant noise within both frames. However, there is a larger estimated noise for the general lottery task than the agricultural decision task. Additionally, there are larger estimates of noise for students with a lower than average context involvement ${ }^{19}$. This is consistent with our prior that the general lottery task relates less to the subjects' real world decision making process and in turn triggers less analytic/systematic thinking.

\footnotetext{
18 The same pattern is observed if analyzing the samples from both universities individually. Results at Bonn University show a highly significant difference (at the $5 \%$ level), while the results from the South Westphalia University of Applied Sciences do not.

${ }^{19}$ Results on the effect of different risk literacy levels on noise don't show a clear. The results are available from the authors upon request.
} 
Table 5: Estimates of risk aversion and Luce structural noise parameter in different iMPL frames by context involvement

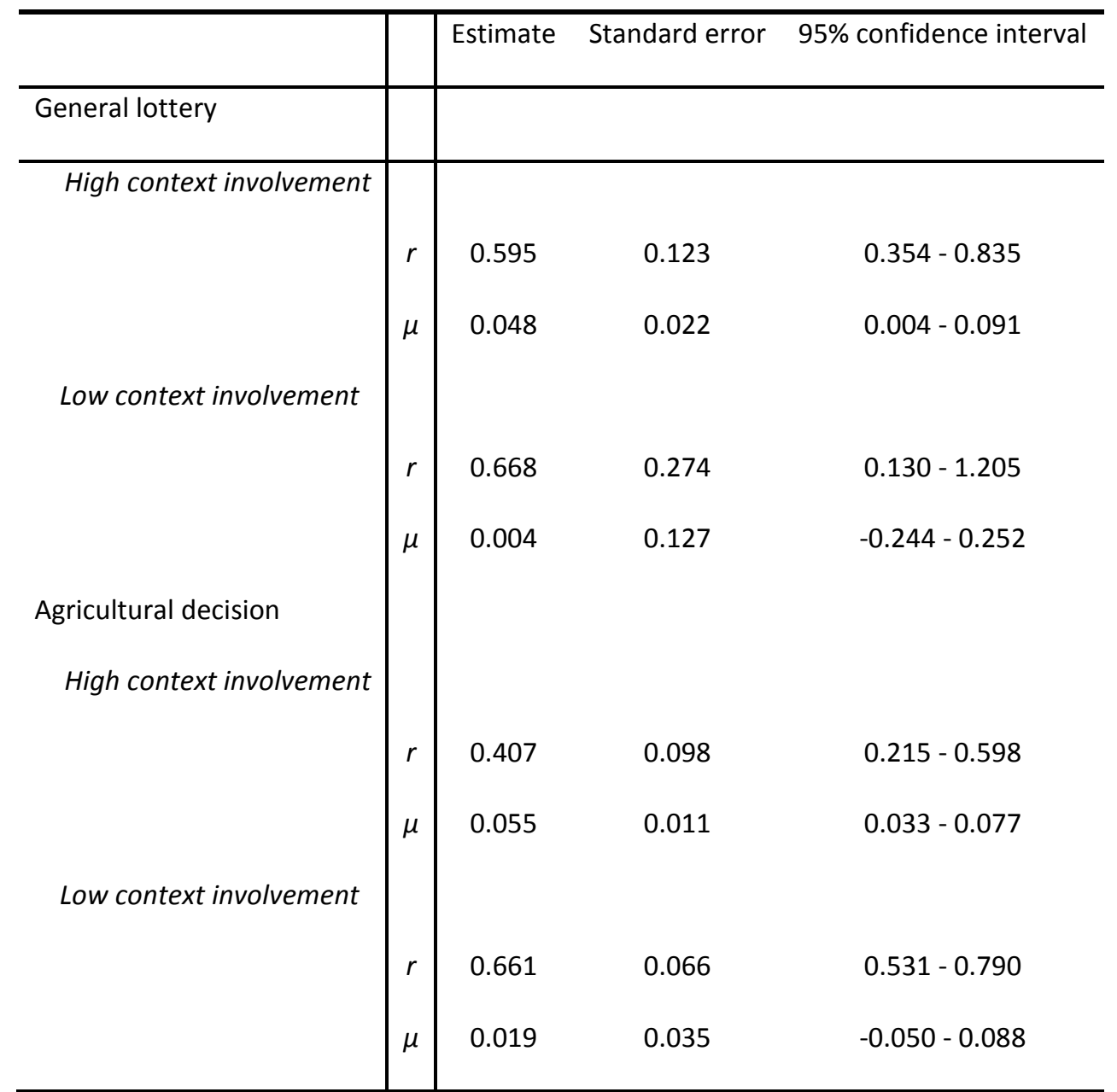

Note that for this estimation only the first switching point in the first table considered. $r$ reflects the estimated risk preference parameter and $\mu$ the estimated structural noise.

Consequently our findings support the hypothesis that within-method consistency increases with increasing task and context involvement.

When analyzing between-method inconsistencies first we examine the correlations of both risk elicitation methods in the two frames (note that we include only within-method consistently behaving subjects in this analysis). Table 6 shows that for both frames of the iMPL the correlation coefficient with the result of the self-assessment task is negative. Thus, herein both risk elicitation tasks point towards the same risk preference direction. Recall that resulting from the structure of both elicitation methods a lower value in the self-assessment and a higher value in the MPL indicate risk aversion. However, the correlation of the risk preferences derived in the general lottery sample and the selfassessment task $(-0.090)$ and the correlation of the risk preferences derived in the agricultural decision sample and the self-assessment task (-0.028) do not significantly differ from each other. Therefore, we reject the hypothesis that both correlations obtained from independent samples are different. 
Table 6: Spearman's rank correlations between CRRA interval mid-points in different frames and selfassessment

\begin{tabular}{lc}
\hline & $r_{s}$ \\
\hline General lottery & -0.090 \\
Agricultural decision & -0.028 \\
\hline Fishers' z-value & 0.43 \\
p-value & 0.64 \\
\hline
\end{tabular}

To test if between-method consistency is driven by the effort spent on the risk elicitation tasks we include the subjects' task involvement in our analysis of between-method inconsistencies. As described above, we split our sample in two independent groups with low and high task involvement. Here we distinguish the two groups by the median of the total time spent on both risk elicitation methods. The correlation of the risk aversion coefficients of the group with low task involvement is positive but not significant $(+0.037)$. Thus, here both risk preference parameters are not consistently measuring risk averse or risk loving preferences, i.e. there are more between-method inconsistencies in this group. In the group with high task involvement we find contrary results. The risk aversion coefficients are here negative correlated $(-0.182)$ at a $10 \%$ significance level, i.e. both risk preference parameter point towards the same direction in this group. Between-method inconsistency is here significantly lower. We cannot reject the hypothesis that both correlation coefficients obtained from independent samples are different. We find a statistically significant difference of the correlation of the CRRA mid-point and self-assessment for students with higher task involvement (see left column in Table 7).

Table 7: Spearman's rank correlations between CRRA interval mid-points in different frames and self-assessment for different levels of involvement

\begin{tabular}{lc|c|c}
\hline & Total sample & General lottery & Agricultural decision \\
\hline High task involvement & $-0.182^{*}$ & $-0.321^{* *}$ & -0.064 \\
Low task involvement & 0.037 & 0.106 & -0.002 \\
\hline Fishers' z-value & 1.59 & 2.07 & 0.3 \\
p-value & 0.11 & 0.04 & 0.77 \\
\hline
\end{tabular}

Note: $*$ and $* *$ denote $10 \%$ and $5 \%$ significance levels, respectively

Furthermore, we analyze if these differences in between-method inconsistencies, depending on the individuals' task involvement, are more severe in the general lottery frame than in the agricultural decision frame. We find that in both frames the correlation coefficients of IMPL and self-assessment are negative for subjects with high task involvement. For subjects with low task involvement in the general lottery frame we find a positive correlation of the risk preference coefficients from both risk preference elicitation methods, thus although not significant there is evidence for between method inconsistency. Contrarily the correlation of the two risk preference coefficients is negative in the agricultural decision framed task, indicating less between method inconsistency (Table 7). 
Nevertheless, we find that this difference in the two frames diminishes in the high task involvement group. When looking at the significance of the difference of the two independent groups (low and high task involvement) we find that it is only significant in the general lottery frame (Fishers'z value $=2.07$, $p$-value $=0.04)$. Between-method inconsistencies are not significantly depending on task involvement in the agricultural decision setting. Thus, if context involvement is triggered, task involvement does not influence between-method inconsistencies. Framing effects play only a minor role when analyzing between-method consistency.

\section{Conclusion}

The subjective risk attitude is decisive for a wide range of decisions taken by economic actors. Over the last decades, a wide range of approaches has been introduced to elicit subjective risk attitudes. However, these elicitation approaches are plagued by inconsistent responses by participants. High inconsistency rates can provoke biased risk preference interpretation and an unavoidable reduction of the explanatory power of the analysis. Thus, the reduction of inconsistent behavior is crucial to improve our understanding of risk preferences. We provide the first study that investigates the role of the decision maker's involvement and how this relates to contextualization of experiments. To this end, we analyze data gathered in experiments considering the subjects' specific differences in context involvement. The methods applied comprise a self-assessment of risk preferences and an incentivecompatible iMPL.

We find evidence that subjects' context and task involvement influence inconsistencies. More specifically, we find that within-method inconsistencies are reduced with increasing task and context involvement. In addition, between-method inconsistencies decrease with increasing task involvement. Adding the subjects' specific contextualization of the risk elicitation method to the analysis of betweenmethod consistency, we find that the importance of task involvement to increase between-method consistency diminishes with increasing contextual involvement. Furthermore, we find that subject specific contextualized elicitation improves accuracy. Thus, we conclude that the contextual embeddedness of a decision making problem is crucial when trying to analyze risk preferences of a specific subject group. Our study was restricted to the analysis of the influence of context and task involvement on between-method inconsistencies and on within-method inconsistencies at one point in time. Further research should also include a time dimension to test for the influence of task and context involvement on within-method inconsistency across time. Furthermore, the analysis of between- method inconsistencies can be extended by increasing the number of compared risk preference elicitation methods. Besides, changing the task wording other exogenous variations like the stake sizes, changes in the visualization of the task or changes of the prominence of the specific task in the experimental design as a whole could be used to extend findings on ways to trigger involvement. In addition to comparing differences in inconsistencies resulting from adaptations of the standard MPL further research should concentrate on comparing noise estimates for different underlying theoretical concepts. For example, noise parameters estimated based on the rank dependent utility model could be compared with the estimated noise parameter assuming EUT.

Although there have been difficulties when trying to project students risk preferences to real decision makers (see Carpenter et al., 2005). We have shown that with increasing involvement students perform better in risk elicitation tasks in terms of consistency. Future research should concentrate on finding ways to trigger students' task and context involvement if they are used as a convenience group in experimental economics. Additionally, research should also concentrate on showing that risk 
preferences of students with higher context involvement could project risk preferences of real decision makers. In turn, this can lead to better predictions of real world decisions and thus improve policy analysis.

Finally, we have shown that by using a real life and subjective context related MPL, involvement can be triggered and consequently the problem of inconsistencies and misinterpretations caused by it can be reduced. 


\section{References}

Abdellaoui, M., Driouchi, A., L'Haridon, 0., 2011. Risk aversion elicitation: reconciling tractability and bias minimization. Theory and Decision 71, 63-80.

Alatas, V., Cameron, L., Chaudhuri, A., Erkal, N., Gangadharan, L., 2009. Subject pool effects in a corruption experiment: A comparison of Indonesian public servants and Indonesian students. Experimental Economics 12, 113-132.

Alekseev, A., Charness, G., Gneezy, U., 2017. Experimental methods: When and why contextual instructions are important. Journal of Economic Behavior \& Organization 134, 48-59.

Andersen, S., Harrison, G.W., Lau, M.I., Rutström, E.E., 2006. Elicitation using multiple price list formats. Experimental Economics 9, 383-405.

Andersen, S., Harrison, G.W., Lau, M.I., Rutström, E.E., 2008. Eliciting Risk and Time Preferences. Econometrica: Journal of the Econometric Society 76, 583-618.

Anderson, L.R., Mellor, J.M., 2009. Are risk preferences stable? Comparing an experimental measure with a validated survey-based measure. Journal of Risk and Uncertainty 39, 137160.

Baltussen, G., Post, T.G., van den Assem, M.J., Wakker, P.P., 2012. Random incentive systems in a dynamic choice experiment. Experimental Economics 15, 418-443.

Bruner, D.M., 2009. Changing the probability versus changing the reward. Experimental Economics 12, 367-385.

Carbone, E., Hey, J.D., 2000. Which error story is best? Journal of Risk and Uncertainty 20, 161-176.

Carpenter, J., Burks, S., Verhoogen, E., 2005. Comparing students to workers: The effects of social framing on behavior in distribution games. Research in Experimental Economics 10, 261-290.

Charness, G., Gneezy, U., Imas, A., 2013. Experimental methods: Eliciting risk preferences. Journal of Economic Behavior \& Organization 87, 43-51.

Charness, G., Viceisza, A., 2016. Three Risk-elicitation Methods in the Field: Evidence from Rural Senegal. Review of Behavioral Economics 3, 145-171.

Cokely, E.T., Galesic, M., Schulz, E., Ghazal, S., Garcia-Retamero, R., 2012. Measuring risk literacy: The Berlin numeracy test. Judgment and Decision Making 7, 25.

Coppola, M., 2014. Eliciting risk-preferences in socio-economic surveys: How do different measures perform? The Journal of Socio-Economics 48, 1-10.

Crosetto, P., Filippin, A., 2013. A theoretical and experimental appraisal of five risk elicitation methods. SOEPaper 547.

Csermely, T., Rabas, A., 2017. How to reveal people's preferences: Comparing time consistency and predictive power of multiple price list risk elicitation methods. Journal of Risk and Uncertainty 53, 107-136.

Dave, C., Eckel, C.C., Johnson, C.A., Rojas, C., 2010. Eliciting risk preferences: When is simple better? Journal of Risk and Uncertainty 41, 219-243.

Deck, C., Lee, J., Reyes, J., 2014. Investing versus gambling: experimental evidence of multidomain risk attitudes. Applied Economics Letters 21, 19-23.

Dohmen, T., Falk, A., Huffman, D., Sunde, U., Schupp, J., Wagner, G.G., 2011. Individual risk attitudes: Measurement, determinants, and behavioral consequences. Journal of the European Economic Association 9, 522-550.

Eckel, C.C., Grossman, P.J., 2002. Sex differences and statistical stereotyping in attitudes toward financial risk. Evolution and human behavior 23, 281-295.

Harrison, G.W., Lau, M.I., Rutström, E.E., 2007. Estimating risk attitudes in denmark: A field experiment. The Scandinavian Journal of Economics 109, 341-368.

Harrison, G.W., Rutström, E.E., 2008. Risk Aversion in the Laboratory, Risk aversion in 
experiments. Emerald (MCB UP ), Bingley, pp. 41-196.

Harrison, G. W., Lau, M. I., \& Rutström, E. E. (2009). Risk attitudes, randomization to treatment, and self-selection into experiments. Journal of Economic Behavior \& Organization, 70(3), 498-507.Hirschauer, N., Musshoff, O., Maart-Noelck, S.C., Gruener, S., 2014. Eliciting risk attitudes - how to avoid mean and variance bias in Holt-and-Laury lotteries. Applied Economics Letters 21, 35-38.

Holt, C.A., Laury, S.K., 2002. Risk aversion and incentive effects. American Economic Review 92, 1644-1655.

Holt, C.A., Laury, S.K., 2005. Risk aversion and incentive effects: New data without order effects. American Economic Review, 902-904.

Jacobson, S., Petrie, R., 2009. Learning from mistakes: What do inconsistent choices over risk tell us? Journal of Risk and Uncertainty 38, 143-158.

Kahneman, D., 2003. Maps of bounded rationality: Psychology for behavioral economics. American Economic Review 93, 1449-1475.

Kahneman, D., Tversky, A., 1979. Prospect theory: An analysis of decision under risk. Econometrica: Journal of the Econometric Society, 263-291.

Levin, I.P., Schneider, S.L., Gaeth, G.J., 1998. All frames are not created equal: A typology and critical analysis of framing effects. Organizational behavior and human decision processes 76, 149-188.

Lévy-Garboua, L., Maafi, H., Masclet, D., Terracol, A., 2012. Risk aversion and framing effects. Experimental Economics 15, 128-144.

Maart-Noelck, S.C., Musshoff, O., 2013. Measuring the risk attitude of decision-makers: are there differences between groups of methods and persons? Australian Journal of Agricultural and Resource Economics 58, 336-352.

McElroy, T., Seta, J.J., 2003. Framing effects: An analytic-holistic perspective. Journal of Experimental Social Psychology 39, 610-617.

Meraner, M., Musshoff, O., Finger, R., submitted. Risk preference elicitation: a German agricultural student sample. Data in Brief.

Stanovich, K.E., West, R.F., 1999. Discrepancies between normative and descriptive models of decision making and the understanding/acceptance principle. Cognitive psychology 38, 349-385.

Starmer, C., 2000. Developments in non-expected utility theory: The hunt for a descriptive theory of choice under risk. Journal of economic literature 38, 332-382.

Steiger, J.H., 1980. Tests for comparing elements of a correlation matrix. Psychological Bulletin 87, 245-251.

Thoma, C., 2015. Under- versus overconfidence: an experiment on how others perceive a biased self-assessment. Experimental Economics 19, 218-239.

Tversky, A., Kahneman, D., 1986. Rational choice and the framing of decisions. The Journal of Business 59, 251-278.

Vollmer, E., Hermann, D., Mußhoff, O., 2017. Is the risk attitude measured with the Holt and Laury task reflected in farmers' production risk? European Review of Agricultural Economics, 1-26.

Wagner, G.G., Frick, J.R., Schupp, J., 2007. The German Socio-Economic Panel study (SOEP)evolution, scope and enhancements. SOEPaper 1.

Wilcox, N.T., 2008. Stochastic models for binary discrete choice under risk: A critical primer and econometric comparison, in: Cox, J.C., Harrison, G.W. (Eds.), Risk aversion in experiments. Emerald Group Publishing Limited, online: 08 Mar 2015, pp. 197-292. 


\section{Appendix A}

Table 1A: Summary statistics of sociodemographic characteristics and risk preferences

\begin{tabular}{|c|c|c|c|}
\hline Risk Elicitation Method & "Measurement Description & Mean & SD \\
\hline CRRA interval mid-point & iMPL CRRA interval mid-point & 0.57 & 0.56 \\
\hline Self-assessment & 0 if very risk averse; ...; 10 if very risk loving & 4.64 & 2.65 \\
\hline Variable Name & Variable Definition & & \\
\hline Gender & 1 if female & 0.50 & 0.50 \\
\hline Age & Years & 23.82 & 2.55 \\
\hline Optimism & $\begin{array}{l}\text { Difference of life satisfaction in a year and life satisfaction today (both } \\
\text { measured on a scale from } 0 \text { to } 10 \text { ) }\end{array}$ & 0.69 & 1.23 \\
\hline Risk literacy score & $\begin{array}{l}1 \text { = poor numerical reasoning; } 2 \text { = rather poor numerical reasoning; } 3= \\
\text { good numerical reasoning; } 4 \text { = very good numerical reasoning } \\
\text { (according to Cokely et al. (2012)) }\end{array}$ & 2.85 & 1.16 \\
\hline Education mother & $\begin{array}{l}\text { Mothers highest education according to the German schooling system: } \\
\text { 1if no degree obtained;...; } 9 \text { if PhD degree obtained }\end{array}$ & 4.56 & 1.87 \\
\hline $\begin{array}{l}\text { Context involvement } \\
\text { score }\end{array}$ & Sum of involvement factors described below & 1.74 & 1.82 \\
\hline Rural origin & 0.5 if area of growing up has less than 20,000 inhabitants & & \\
\hline $\begin{array}{l}\text { Growing up on farm } \\
\text { holding }\end{array}$ & 1 if grew up on a farm & & \\
\hline Parents are farmers & 1 if parents are farmers & & \\
\hline $\begin{array}{l}\text { Succession of farm } \\
\text { holding intended }\end{array}$ & $\begin{array}{l}0.5 \text { if probably no succession is intended; } 1 \text { if probably succession is } \\
\text { intended; } 2 \text { if succession is intended }\end{array}$ & & \\
\hline Agricultural Internship & $\begin{array}{l}0.5 \text { if internship time is less or equal to } 6 \text { months; } 1 \text { if internship time } \\
\text { is more than } 6 \text { months }\end{array}$ & & \\
\hline Vocational training & 1 if agriculture specific vocational training obtained & & \\
\hline Agricultural school & 1 if three year agricultural school degree & & \\
\hline Master exam & 1 if five year agricultural school degree (master) & & \\
\hline $\begin{array}{l}\text { Higher agricultural } \\
\text { education }\end{array}$ & 1 if higher agricultural education obtained & & \\
\hline Time iMPL & Time spent on iMPL in minutes & 3.40 & 2.63 \\
\hline Time Self-assessment & Time spent on self-assessment of risk preferences in minutes & 0.43 & 0.62 \\
\hline
\end{tabular}


Table 2A: Summary statistics general lottery and agricultural decision frame

\begin{tabular}{|c|c|c|c|c|c|c|}
\hline \multirow[b]{2}{*}{ Variable } & \multicolumn{3}{|c|}{$\begin{array}{l}\text { General lottery } \\
\qquad \mathbf{N}=127\end{array}$} & \multicolumn{3}{|c|}{$\begin{array}{l}\text { Agricultural decision } \\
\qquad \mathrm{N}=117\end{array}$} \\
\hline & Mean & SD & NA & Mean & SD & NA \\
\hline $\begin{array}{l}\text { iMPL CRRA interval } \\
\text { mid-point }\end{array}$ & 0.563 & 0.502 & 2 & 0.583 & 0.627 & \\
\hline Self-assessment & 4.638 & 2.692 & & 4.658 & 2.620 & \\
\hline Gender (female) & 0.512 & 0.500 & & 0.470 & 0.499 & \\
\hline Age & 24.685 & 2.569 & & 24.915 & 2.501 & \\
\hline Opt & 0.677 & 1.223 & & 0.701 & 1.250 & \\
\hline Risk literacy score & 2.890 & 1.173 & & 2.803 & 1.150 & \\
\hline Education mother & 4.411 & 1.850 & 3 & 4.713 & 1.883 & 2 \\
\hline $\begin{array}{l}\text { Context } \\
\text { involvement score }\end{array}$ & 1.583 & 1.666 & & 1.902 & 1.968 & \\
\hline Time iMPL & 3.043 & 1.974 & & 3.792 & 3.143 & \\
\hline $\begin{array}{l}\text { Time Self- } \\
\text { assessment }\end{array}$ & 0.387 & 0.513 & & 0.471 & 0.716 & \\
\hline
\end{tabular}


Fig. 1A: Distribution of the CRRA interval mid-point in two different iMPL frames

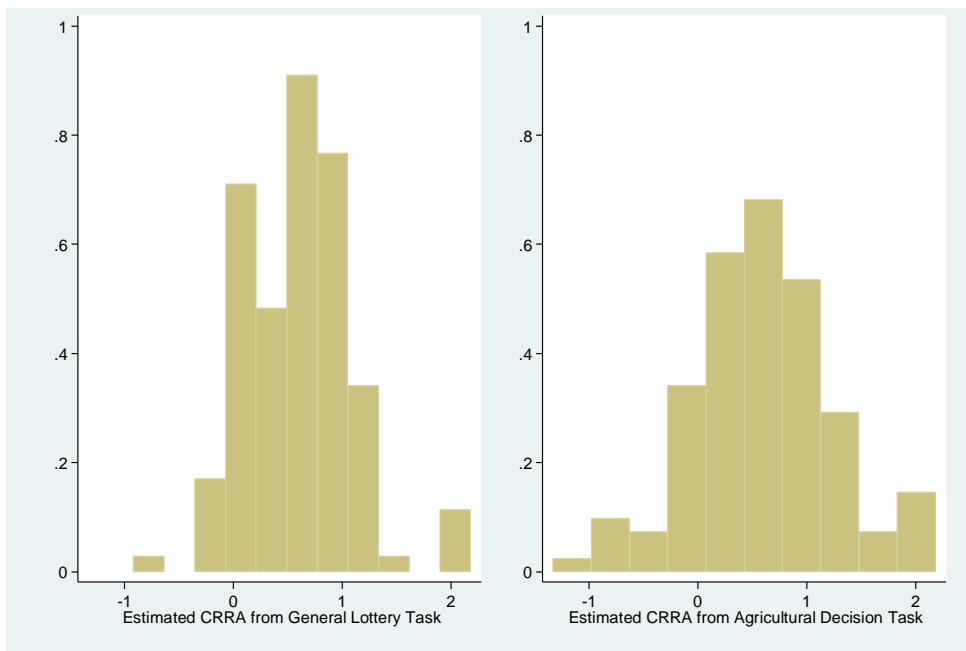

Fig. 2A: Distribution of self-assessment task

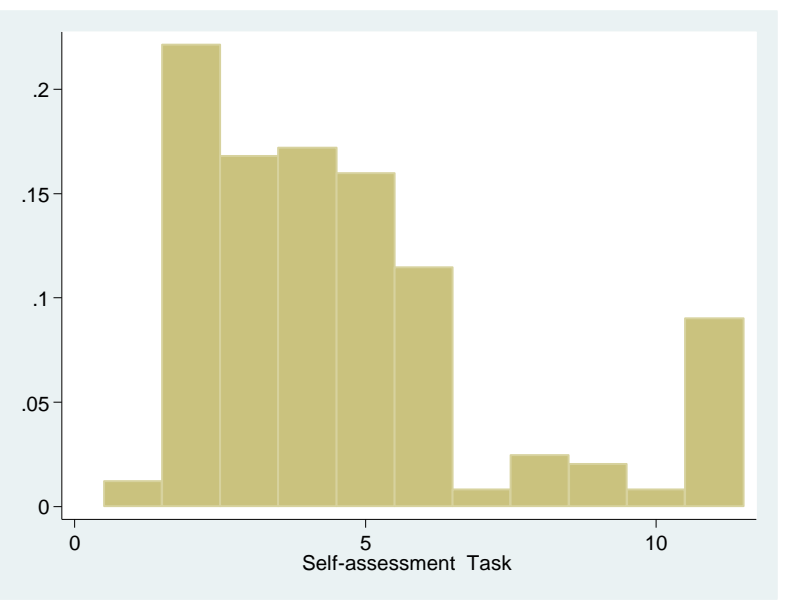

\section{Appendix B}

\section{First screen}

Welcome to the experiment!

In the following we will offer you various situations and options to choose from. We would like to get to know something about your behavior in different situations/scenarios. There are no 'right' or 'wrong' decisions!

For all participants there is a chance to be drawn at random for a win of $87 €$. We will inform you about your payoff via e-mail. The payoff of the win will be carried out immediately after the evaluation of the experiment.

The experiment will take approx. 20 minutes. Of course, your data will be treated confidentially and the data will be evaluated anonymously. For further inquiries please contact: m.meraner@ilr.unibonn.de. 


\section{Second screen}

Please read carefully through the following description of your chances to win:

What can you win? The payoff for each participant can amount up to $87 €$ (first part: $77 €+$ second part: $10 €)$.

How can you win? In the first part of the experiment you will be presented a table with ten rows. For each row you will have to choose between option A and option B. The decision (row), that will be relevant for your payoffs, will be determined by the first draw out of a lottery with ten balls. In the case that row 4 will be identified, you were asked to choose between option $A$ ( $40 \%$ probability/chance $40.000 €$ und $60 \%$ probability/chance $32.000 €$ ) and option B (40\% probability/chance $77.000 €$ and $60 \%$ probability/chance $2.000 €$ ). Your win will be multiplied by the factor $1 / 1.000$.

Example: If we assume that you have chosen option $B$ in the randomly selected row 4 . In the second draw, the numbers 1 to 4 ( $=40 \%$ chance) lead to a payoff of $77 €$, the numbers $5-10$ ( $=60 \%$ chance) result in a payoff of $2 €$. In the second part we will ask you to solve some arithmetic questions. For the correct answer to these tasks, the participants, who were selected as winners, receive additionally $10 €$.

Who can win? $10 \%$ of all participants will be drawn at random to receive the payment.

\section{Third screen: control question}

To make sure, that you understood the method of payment for the reward of your participation, please answer the following question:

Please assume that you were drawn randomly as one of the winners. In the first draw, which serves to identify the row, that will be relevant for the payment, 4 out of 10 was drawn. This means that the decision row 4 will be relevant for your payment. Assume furthermore, that you have chosen option $A$ in the relevant decision (marked with the blue dot in the table on the right).

Example: (see Figure 1)

The second draw results in number 7 . What is the amount of your payoff?

(1.000 $€$ in the lottery $=1 €$ payoff).

(Right answer not shown to participants: 32) 


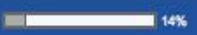

Um sicher zu gehen, dass Sie den Auszahlungsmodus zur Belohung Ihrer Teilnahme verstanden haben, bitten wir Sie, folgende Frage zu beantworten:

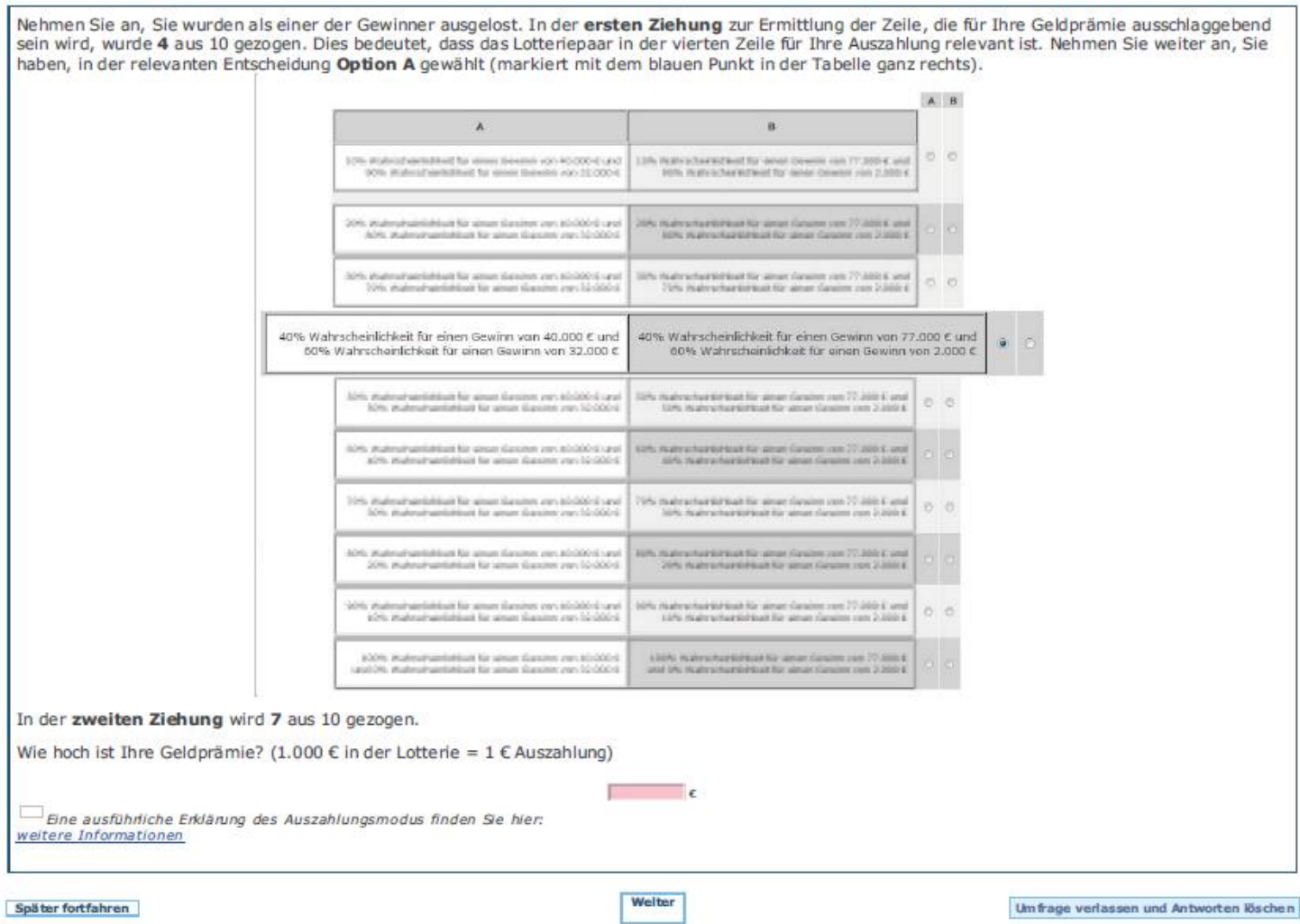

Fig 1B: Third screen: control question

Only one of the following two screens is shown:

\section{Fourth screen A: General lottery task}

In each row of the following table you can choose between two lotteries ( $A$ and $B$ ). With certain chances/ probabilities you get for lottery $A$ a payoff of $40.000 €$ or $32.000 €$ and for lottery $B$ a payoff of $77.000 €$ or $2.000 €$. Please decide between lottery $A$ and $B$ for every row of the table.

\section{Fourth screen B: Agricultural decision task}

Assume that after successfully completing your studies you are offered to make an agricultural investment. Here you will get with different associated probabilities for investment $A$ a return of $40,000 €$ or $32,000 €$ and for investment $B$ a return of $77,000 €$ or $2,000 €$. You can choose in the following table in each row between the two investment options ( $A$ or $B$ ). Please decide between investment $A$ and $B$ for every row of the table. 
Sie kơnnen imfolgenden Tableau in jeder Zeile zwischen zwei Lotterien (A und B) wählen. Mit bestimmten Wahrscheinlichkeiten erhalten Sie für Lotterie A einen Gewinn von $40.000 \mathrm{C}$ oder $32.000 \mathrm{C}$ und für Lotterie B einen Gewinn von $\mathbf{7 7 . 0 0 0 ~ C}$ oder $\mathbf{2 . 0 0 0 \mathrm { C }}$

Bitte entscheiden Sie sich in ieder Zeile für Lotterie A oder B.

\begin{tabular}{|c|c|c|}
\hline & & \multirow{2}{*}{ A B } \\
\hline A & B & \\
\hline $\begin{array}{l}10 \% \text { Wa hrschen ichkeit fur einen Gewinn von } 40.000 € \text { und } \\
90 \% \text { Wahrscheinlichket für einen Gewinn von } 32.000 €\end{array}$ & $\begin{array}{l}10 \% \text { Wahrscheinichkeit für einen Gewhn von } 77.000 € \text { und } \\
90 \% \text { Wahrscheinichket fur einen Gewinn von } 2.000 €\end{array}$ & - 0 \\
\hline $\begin{array}{l}20 \% \text { Wa hrschenichikelt fur einen Gewinn von } 40.000 € \text { und } \\
80 \% \text { Wahrscheinlichiket für einen Gewinn von } 32.000 €\end{array}$ & $\begin{array}{l}20 \% \text { Wahrscheinlichkeit für einen Gewhn von } 77.000 € \text { und } \\
80 \% \text { Wahrscheinichket fur einen Gewinn von } 2.000 €\end{array}$ & - 0 \\
\hline $\begin{array}{l}30 \% \text { Wa hischenkichkelt fur einen Gewinn von } 40.000 € \text { und } \\
70 \% \text { Wahrscheinlichket für einen Gewinn von } 32.000 €\end{array}$ & $\begin{array}{l}30 \% \text { Wahrscheinlichkeit für einen Gewhn von } 77.000 € \text { und } \\
70 \% \text { Wahrscheinichket fur einen Gewinn von } 2.000 €\end{array}$ & \\
\hline $\begin{array}{l}40 \% \text { Wa hischenichikeit fur einen Gewinn von } 40.000 € \text { und } \\
60 \% \text { Wahrscheinlichket für einen Gewinn von } 32.000 €\end{array}$ & $\begin{array}{l}40 \% \text { Wahrscheinlichkeit fur einen Gewhn von } 77.000 € \text { und } \\
60 \% \text { Wahrscheinichket fur einen Gewinn von } 2.000 €\end{array}$ & - 0 \\
\hline $\begin{array}{l}50 \% \text { Wa hrschenichikelt fur einen Gewinn von } 40.000 € \text { und } \\
50 \% \text { Wahrscheinlichket für einen Gewinn von } 32.000 €\end{array}$ & $\begin{array}{l}50 \% \text { Wahrscheinlichkeit für einen Gewhn von } 77.000 € \text { und } \\
50 \% \text { Wahrscheinlichket fur einen Gewinn von } 2.000 €\end{array}$ & \\
\hline $\begin{array}{l}60 \% \text { Wa hrschenichikelt fur einen Gewinn von } 40.000 € \text { und } \\
40 \% \text { Wahrscheinlichiket für einen Gewinn von } 32.000 €\end{array}$ & $\begin{array}{l}60 \% \text { Wahrscheinlichkeit für einen Gewhn von } 77.000 € \text { und } \\
40 \% \text { Wahrscheinichket fur einen Gewinn von } 2.000 €\end{array}$ & \\
\hline $\begin{array}{l}70 \% \text { Wa hrschehichkelt fur einen Gewinn von } 40.000 € \text { und } \\
30 \% \text { Wahrscheinlichiket fur einen Gewinn von } 32.000 €\end{array}$ & $\begin{array}{l}70 \% \text { Wahrscheinlichkelt für einen Gewhn von } 77.000 € \text { und } \\
30 \% \text { Wahrscheinlichket fur einen Gewinn von } 2.000 €\end{array}$ & $0 *$ \\
\hline $\begin{array}{l}80 \% \text { Wa hrschenichkeit fur einen Gewinn von } 40.000 € \text { und } \\
20 \% \text { Wahrscheinlichiket für einen Gewinn von } 32.000 €\end{array}$ & $\begin{array}{l}80 \% \text { Wahrscheinlichkelt für einen Gewhn von } 77.000 € \text { und } \\
20 \% \text { Wahrscheinichiket fur einen Gewinn von } 2.000 €\end{array}$ & $\circ \bullet$ \\
\hline $\begin{array}{l}90 \% \text { Wa hrschenichikeit fur einen Gewinn von } 40.000 € \text { und } \\
10 \% \text { Wahrscheinlichket für einen Gewinn von } 32.000 €\end{array}$ & $\begin{array}{l}90 \% \text { Wahrscheinlichkelt für einen Gewhn von } 77.000 € \text { und } \\
10 \% \text { Wahrscheinichiket fur einen Gewinn von } 2.000 €\end{array}$ & $0 \bullet$ \\
\hline $\begin{array}{l}100 \% \text { Wa hischenkichkelt fur einen Gewinn von } 40.000 € \text { und } \\
0 \% \text { Wahrscheinlichket fur einen Gewinn von } 32.000 €\end{array}$ & $\begin{array}{l}100 \% \text { Wahrscheinlichkelt fur einen Gewhn von } 77.000 € \text { und } \\
0 \% \text { Wehrscheinlchket fur einen Gewinn von } 2.000 €\end{array}$ & 0 \\
\hline
\end{tabular}

Fig 2B: Fourth screen: General lottery task

\section{Fifth screen: Self-assessment}

How do you see yourself: are you generally a person who is fully prepared to take risks or do you try to avoid taking risks? Please tick a box on the scale, where the value 0 means: 'not at all willing to take risks' and the value 10 means: 'very willing to take risks'.

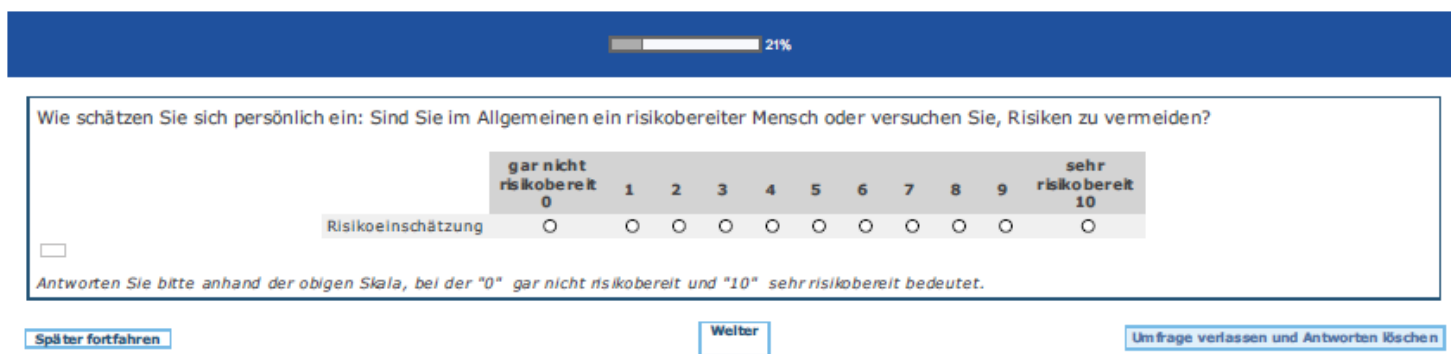

Fig 3B: Fifth screen: Self-assessment task 